\title{
Price Increases and New Drugs Drive Increased Expenditures for Multiple Sclerosis
}

\author{
Jeremy A. Schafer, PharmD, MBA; Brent W. Gunderson, PharmD; \\ and Patrick P. Gleason, PharmD, BCPS, FCCP
}

$\mathrm{M}$ ultiple sclerosis (MS) affects approximately 400,000 Americans. ${ }^{1}$ Most patients are diagnosed between 20 and 50 years of age, and the disease develops in twice as many women as men. ${ }^{1}$ MS is characterized by scattered areas of inflammation, demyelination, and axonal injury affecting the brain, optic nerves, and spinal cord. ${ }^{2}$ Inflammatory demyelination can be accompanied by clinical symptoms, termed relapses, followed by some degree of recovery, producing the classic relapsing-remitting MS (RRMS) seen early in the disease. ${ }^{2}$ Secondary progressive MS (SPMS) occurs when persistent signs of central nervous system (CNS) dysfunction develop after a relapse, and the disease progresses between relapses. ${ }^{2}$ RRMS develops into secondary progressive MS in $50 \%$ of patients within 10 years and $75 \%$ of patients within 25 years. ${ }^{1}$ Primary progressive MS (PPMS) occurs when the clinical course is gradually progressive and is the diagnosis in approximately $20 \%$ of MS cases. ${ }^{1}$ Clinical course and disability vary between patients and depend on MS disease type. ${ }^{2}$

The medical and pharmacy costs of MS are substantial. Pope et al. (2002) analyzed the cost of MS in beneficiaries with private insurance, Medicare, or Medicaid. Excluding prescription drug costs from all comparisons because Part D coverage was not in effect at the time of the study, members with MS enrolled in private insurance had 3 times the average all-cause medical expenditures compared with non-MS members (\$6,329 vs. $\$ 2,001){ }^{3}$ Medicare members with MS had double the medical expenditures compared with members without MS $(\$ 13,048$ vs. $\$ 6,006)$. Finally, members with MS covered by Medicaid had 2.5 times the medical costs compared with members without MS (\$10,358 vs. $\$ 4,111)$. In the private insurance and Medicaid cohorts, prescription drug costs were also higher in the MS group. ${ }^{3}$

Using survey data and estimated costs for a random sample of participants in the North American Research Committee on MS (NARCOMS) patient registry who reported use of 1 or more of the 4 MS biologic agents, Kobelt et al. (2006) estimated that the total mean annual direct (inpatient and outpatient services, prescriptions) and indirect costs (loss of productivity, work loss or reduction) of MS were $\$ 47,215$ per patient (in 2004 dollars). ${ }^{4}$ Direct medical and nonmedical costs including "informal care from family and friends" accounted for $\$ 29,634$ per patient per year (PPPY). ${ }^{4}$ The single largest expenditure in the direct cost category was MS biologics at $\$ 16,050$ PPPY or $34.0 \%$ of the overall direct and indirect costs. ${ }^{4}$ Price inflation for existing drugs and the introduction of new agents for MS promise to further increase the cost of MS and present a growing challenge for payers.

In this issue of JMCP, Asche et al. analyze the all-cause health care utilization and costs for patients newly diagnosed with MS or with at least 1 claim for an injectable drug for MS. ${ }^{5}$ The study involved an analysis of the Medstat MarketScan Commercial Claims and Encounters database composed of approximately 8 million beneficiaries from 45 U.S. commercial health plans. The study compared 1,411 patients with MS with 7,055 healthy subjects without MS. The analysis found that patients with MS were 2 times as likely to visit the ER, 1.2 times as likely to visit the doctor's office, and 2.4 times as likely to have physical, occupational, or speech therapy compared with patients without MS. These increases in utilization of health care created a significant difference in 12-month direct health care costs: $\$ 18,829$ for MS patients compared with $\$ 4,038$ for patients without MS. Pharmacy costs per member were 7.5 times as high in patients with MS compared with patients without MS $(\$ 6,151$ vs. $\$ 817)$.

The analysis by Asche et al. has limitations in understanding the cost impact of biologics for MS. First, only $30.8 \%$ of MS patients in the sample received treatment with MS biologics, compared with $100 \%$ of the MS patients in the NARCOMS study by Kobelt et al. ${ }^{4}$ The difference in utilization of biologic agents explains some of the disparity in PPPY pharmacy expenditures on MS biologics between NARCOMS $(\$ 16,050)$ and Asche et al. (\$4,436), despite older data (from 2004) in the NARCOMS study. ${ }^{4}$ Second, the analysis by Asche et al. spanned the period from 2004 through 2006, and the arrival of new agents and continued price inflation are complicating factors. However, the authors did adjust the costs to 2010 dollars to give a current picture of the costs of therapy.

Kunze et al. published an analysis of cost trends and utilization of MS agents for the time period 2004 through $2007 .{ }^{6}$ The study involved 9 million commercially insured members and the 4 self-injectable MS biologic agents: glatiramer, interferon (IFN) beta-la subcutaneous (SC), IFN beta-lb SC, and IFN beta-1b intramuscular (IM). Claims for MS biologics ranged between 82 and 83 claims per 100,000 members during the 45-month study period. However, spending for MS biologics increased from 1.8\% of total pharmacy spending in 2004 
Price Increases and New Drugs Drive Increased Expenditures for Multiple Sclerosis

\section{TABLE 1 Medical and Pharmacy Cost Trends 2006 to 2009 for 361}

Commercially Insured Members with MS Followed for 4 Years $^{\mathrm{a}}$

\begin{tabular}{|c|c|c|c|c|c|c|c|c|c|c|c|c|c|c|}
\hline \multirow[b]{2}{*}{ Year } & \multicolumn{2}{|c|}{$\begin{array}{l}\text { Total Medical } \\
\text { Expenditures }\end{array}$} & \multicolumn{2}{|c|}{$\begin{array}{l}\text { Total Pharmacy } \\
\text { Expenditures }\end{array}$} & \multirow[b]{2}{*}{$\begin{array}{c}\% \\
\text { Pharmacy }\end{array}$} & \multicolumn{3}{|c|}{$\begin{array}{c}\text { Pharmacy } \\
\text { Expenditure Trend }\end{array}$} & \multicolumn{3}{|c|}{$\begin{array}{c}\text { Medical } \\
\text { Expenditure Trend }\end{array}$} & \multicolumn{3}{|c|}{$\begin{array}{c}\text { Combined } \\
\text { (Medical and Pharmacy) }\end{array}$} \\
\hline & $\mathrm{N}^{\mathrm{b}}$ & Total Paid & $\mathrm{N}^{\mathrm{b}}$ & Total Paid & & PPPY & \begin{tabular}{|c|} 
Compared \\
with Previous \\
Year
\end{tabular} & CAGR & PPPY & \begin{tabular}{|c|} 
Compared \\
with Previous \\
Year
\end{tabular} & CAGR & PPPY & \begin{tabular}{|c|} 
Compared \\
with Previous \\
Year
\end{tabular} & CAGR \\
\hline 2006 & 361 & $\$ 4,525,284$ & 354 & $\$ 6,179,083$ & $57.7 \%$ & $\$ 17,117$ & NA & NA & $\$ 12,535$ & NA & NA & $\$ 29,652$ & NA & NA \\
\hline 2007 & 360 & $\$ 4,460,924$ & 350 & $\$ 6,218,874$ & $58.2 \%$ & $\$ 17,227$ & $0.6 \%$ & $0.6 \%$ & $\$ 12,357$ & $-1.4 \%$ & $-1.4 \%$ & $\$ 29,584$ & $-0.2 \%$ & $-0.2 \%$ \\
\hline 2008 & 361 & $\$ 5,290,883$ & 351 & $\$ 6,998,839$ & $56.9 \%$ & $\$ 19,387$ & $12.5 \%$ & $6.4 \%$ & $\$ 14,656$ & $18.6 \%$ & $8.1 \%$ & $\$ 34,044$ & $15.1 \%$ & $7.1 \%$ \\
\hline 2009 & 360 & $\$ 5,623,476$ & 349 & $\$ 7,947,356$ & $58.6 \%$ & $\$ 22,015$ & $13.6 \%$ & $8.8 \%$ & $\$ 15,577$ & $6.3 \%$ & $7.5 \%$ & $\$ 37,592$ & $10.4 \%$ & $8.2 \%$ \\
\hline
\end{tabular}

to $2.4 \%$ in 2007 , a $33 \%$ increase. In absolute terms, cost per member per month (PMPM) increased by $56.8 \%$ from $\$ 1.11$ in the first quarter of 2004 to $\$ 1.74$ PMPM in the third quarter of 2007. As utilization was flat during this period, the average annual price increase of approximately $12 \%$ drove the increase in overall expenditures. ${ }^{6}$ This inflationary trend has continued with an annual growth rate in ingredient cost per prescription of $17.3 \%$ from the second quarter of 2007 through the second quarter of $2010 .{ }^{7}$

\section{Benchmark Analysis of Medical and Pharmacy Costs for Commercial Health Plan Members with MS}

In order to understand the total cost of care trend among individuals with MS, we analyzed medical and pharmacy administrative pharmacy claims to identify a cohort and then followed the cohort for 4 years. This MS cohort was identified through an analysis of pharmacy and medical claims data for approximately 1.4 million commercial health plan members for the period from 2006 through 2009 to examine the total costs and rate of cost increase for MS management. In this midwestern commercial health plan, 390,108 members were continuously enrolled for the 4-year period. Members eligible for analysis were required to have been continuously enrolled for the 4-year duration, and meet at least 1 of 2 criteria: (a) at least 1 medical claim with an MS-related International Classification of Diseases, Ninth Revision, Clinical Modification (ICD-9-CM) diagnosis code of 340 in January 2006 and in each subsequent year (2007, 2008, and 2009); or (b) at least 1 MS medical claim in the first quarter of 2006 and a pharmacy claim for an MS drug (Generic Product Identifier [GPI, Wolters Kluwer Health, Indianapolis, IN] codes: 62400030102120, 62400030106420, $62403060452020,62403060452040,62403060452060$, $62403060456420,62403060456430,62403060502120$, $62405050001320,62406030007420,62407025100120)$ in January 2006. Costs were total allowed amounts (plan and member) for all medical and pharmacy claims. A total of 361 patients met analytic criteria. Medical costs (without pharmacy) increased by 24.3\% from \$12,535 PPPY in 2006 to $\$ 15,577$ in 2009 (Table 1). Combined medical and pharmacy costs increased by nearly $27 \%$ from $\$ 29,652$ PPPY in 2006 to $\$ 37,592$ (Table 1). The cost trends presented here are for a fixed cohort followed over time and may be confounded by worsening disease resulting in increased medical and pharmacy expenditures. However, pharmacy biologic expenditures are unlikely to be influenced by worsening disease as combination biologic therapy is not approved by the U.S. Food and Drug Administration (FDA).

Price inflation has led to an increasing cost burden on patients as well. ${ }^{6}$ An analysis of internal data from our 2006 to 2010 commercial book of business of approximately 9.0 million members indicates that mean member out-of-pocket cost share per prescription claim for MS therapies nearly doubled from 2006 to 2009 (Table 2). Prescription claims in the analysis of cost per prescription were adjusted by days supply (0-34 days $=1$ claim, 35-68 days $=2$ claims, 69-120 days $=3$ claims $)$. These data support the findings of Asche et al. ${ }^{5}$ and Kunze et al. ${ }^{6}$ regarding the growing medical and pharmacy costs of MS.

\section{Cost-Effectiveness of MS Biologics}

The cost-effectiveness of the MS biologics has been analyzed in previous studies in JMCP with conflicting results. Goldberg et al. (2009) analyzed the 2-year cost effectiveness for the 4 agents (IFNs and glatiramer) when used first-line for RRMS. The estimated costs per relapse avoided were $\$ 80,589, \$ 87,061$, $\$ 88,310$, and $\$ 141,721$ for IFN beta-la SC, IFN beta-1b SC, glatiramer, and IFN beta-la IM, respectively. ${ }^{8}$ Alternatively, Bell et al. (2007) used a Markov model to estimate the cost per quality-adjusted life year (QALY) gained for the 4 self-administered MS biologics. In contrast to Goldberg et al., this study found glatiramer to be the most cost-effective at $\$ 258,465$ per 
QALY. IFN beta-la IM, IFN beta-1b SC, and IFN beta-la SC had costs per QALY of $\$ 303,968, \$ 310,691$, and $\$ 416,301$, respectively. ${ }^{9}$ Payers can expect cost-effectiveness of the MS biologics to erode as price inflation continues.

\section{Recent Drug Approvals for MS Enlarge Opportunity for Utilization Management}

The pharmacy costs of managing MS are likely to increase further with the approval of new therapies. Dalfampridine was approved by the FDA in January 2010 to improve walking in patients with MS as demonstrated by an increase in walking speed. ${ }^{10}$ Dalfampridine does not prevent MS relapses; instead, dalfampridine is theorized to exert its effects on walking ability by blocking potassium channels and improving conduction in motor neurons damaged by MS. ${ }^{10}$ Dalfampridine clinical trials included patients with PPMS and thus may expand the pool of MS patients eligible for treatment with prescription agents. The average wholesale price (AWP) of a $10 \mathrm{mg}$ dalfampridine tablet is $\$ 21.12$, and 1 month of therapy would cost $\$ 1,267.20 .^{11}$ This cost would be in addition to, rather than replacing, any cost associated with MS biologics pharmacotherapy.

In September 2010, fingolimod was approved by the FDA as the first oral MS agent, with the specific indication to reduce relapses and delay disability progression in patients with relapsing forms of MS. ${ }^{12}$ The AWP of fingolimod is $\$ 158$ per capsule or $\$ 4,740$ per month. ${ }^{11}$ The cost of fingolimod is significantly higher than those of the competing injectable MS biologics.

MS is a devastating disease, and patients should be managed with approved therapies to reduce relapses and manage disability. However, payers must be prepared to manage the MS category to ensure cost-effective use. MS drug class maturation provides payers with greater opportunities to derive cost savings through tools like formulary, benefit design, and utilization management programs.

Clinical guidelines presently recommend initiating therapy in patients with RRMS using either an IFN or glatiramer, and the guidelines do not prefer one IFN product over another. ${ }^{13,14}$ Comparative trials have shown a possible advantage in reduced relapse rates with IFN beta-la SC or IFN beta-lb SC compared with IFN beta-la IM. ${ }^{15}$ However, the effect on long-term disability between these agents is unclear. ${ }^{15}$ Comparative data among IFN beta-la SC, IFN beta-1b SC, and glatiramer have demonstrated comparable efficacy in reducing relapse rates. ${ }^{15}$ The similar efficacy and safety of approved therapies presents an opportunity for payers to prefer 1 or 2 agents on the formulary. Payers should ensure the tier differential is substantial enough to encourage use of preferred products and shift market share to formulary agents. Data are limited on MS biologics in other types of MS, and no MS biologic or fingolimod has been shown to be effective in PPMS.

\section{TABLE 2 Member Cost Share Per} 30-Day Supply for MS Drugs ${ }^{\mathrm{a}, \mathrm{b}}$

\begin{tabular}{|c|c|c|c|c|c|}
\hline Year & Quarter & Mean & Median & $\begin{array}{c}\text { First } \\
\text { Quartilec }^{\mathrm{c}}\end{array}$ & $\begin{array}{c}\text { Third } \\
\text { Quartile }^{\mathrm{c}}\end{array}$ \\
\hline \multirow[t]{4}{*}{2006} & 1 & $\$ 68$ & $\$ 30$ & $\$ 20$ & $\$ 40$ \\
\hline & 2 & $\$ 45$ & $\$ 25$ & $\$ 17$ & $\$ 33$ \\
\hline & 3 & $\$ 41$ & $\$ 25$ & $\$ 15$ & $\$ 30$ \\
\hline & 4 & $\$ 40$ & $\$ 25$ & $\$ 15$ & $\$ 35$ \\
\hline \multirow[t]{4}{*}{2007} & 1 & $\$ 87$ & $\$ 30$ & $\$ 20$ & $\$ 50$ \\
\hline & 2 & $\$ 50$ & $\$ 30$ & $\$ 17$ & $\$ 35$ \\
\hline & 3 & $\$ 46$ & $\$ 25$ & $\$ 15$ & $\$ 35$ \\
\hline & 4 & $\$ 45$ & $\$ 25$ & $\$ 15$ & $\$ 35$ \\
\hline \multirow[t]{4}{*}{2008} & 1 & $\$ 111$ & $\$ 30$ & $\$ 20$ & $\$ 50$ \\
\hline & 2 & $\$ 59$ & $\$ 30$ & $\$ 20$ & $\$ 40$ \\
\hline & 3 & $\$ 54$ & $\$ 30$ & $\$ 17$ & $\$ 40$ \\
\hline & 4 & $\$ 50$ & $\$ 30$ & $\$ 17$ & $\$ 40$ \\
\hline \multirow[t]{4}{*}{2009} & 1 & $\$ 153$ & $\$ 30$ & $\$ 25$ & $\$ 55$ \\
\hline & 2 & $\$ 68$ & $\$ 30$ & $\$ 20$ & $\$ 50$ \\
\hline & 3 & $\$ 59$ & $\$ 30$ & $\$ 20$ & $\$ 45$ \\
\hline & 4 & $\$ 55$ & $\$ 30$ & $\$ 17$ & $\$ 45$ \\
\hline \multirow[t]{3}{*}{2010} & 1 & $\$ 193$ & $\$ 40$ & $\$ 30$ & $\$ 75$ \\
\hline & 2 & $\$ 84$ & $\$ 35$ & $\$ 25$ & $\$ 50$ \\
\hline & 3 & $\$ 78$ & $\$ 35$ & $\$ 24$ & $\$ 50$ \\
\hline
\end{tabular}

Annual summaries (all quarters)

\begin{tabular}{l|c|c|c|c}
\hline 2006 & $\$ 48$ & $\$ 25$ & $\$ 16$ & $\$ 35$ \\
\hline 2007 & $\$ 57$ & $\$ 30$ & $\$ 17$ & $\$ 35$ \\
\hline 2008 & $\$ 68$ & $\$ 30$ & $\$ 20$ & $\$ 40$ \\
\hline 2009 & $\$ 82$ & $\$ 30$ & $\$ 20$ & $\$ 50$ \\
\hline $2010^{\text {d }}$ & $\$ 114$ & $\$ 35$ & $\$ 25$ & $\$ 50$ \\
\hline
\end{tabular}

${ }^{a}$ Drugs in analysis include dalfampridine, all 3 interferon agents, glatiramer, and natalizumab processed through the pharmacy benefit. Data are from commercial health plans totaling approximately 9.0 million members. The analysis period was January 1, 2006, through September 30, 2010.

bPharmacy claims were adjusted by days supply: 0-34 days = 1 claim, 35-68 days $=2$ claims, $69-120$ days $=3$ claims .

cFirst and third quartiles are 25 th and 75 th percentiles, respectively (interquartile range).

d3 calendar quarters through September 30, 2010.

Utilization management programs present another opportunity to promote safe use and control MS costs. Step-therapy programs can require trial of one agent prior to another and may prevent concurrent use of 2 relapse-preventing agents, which has not been evaluated for safety or effectiveness. Patients shown to be intolerant to or failing preferred agents could then be approved for nonpreferred therapies. Prior authorization (PA) programs may be implemented to verify appropriate use of fingolimod and other MS agents for only types of MS for which there are efficacy and safety data available. Coverage of dalfampridine should be limited to patients with MS and renewed upon demonstration of efficacy. Responder rates in dalfampridine pivotal trials ranged from 35\%-43\% compared with 8\%-9\% for placebo. ${ }^{16,17}$ Response generally occurred quickly and was sustained during the trial. ${ }^{16,17} \mathrm{PA}$ programs 
should require documentation of efficacy 2 or more months after initiation of therapy. Dalfampridine has been associated with safety concerns including an increased risk of seizure. ${ }^{10}$ Patients failing to demonstrate efficacy should not be approved for continuing therapy.

\section{Benefit Design Considerations and Member Cost Share}

Benefit designs including a fourth cost-share tier or specialty cost-share tier are becoming more common. Part of the function of a specialty cost-share tier is to differentiate specialty products and increase cost share to members. However, payers should exercise caution when utilizing a specialty tier and associated increased cost share. Gleason et al. (2009) examined the rate of prescription abandonment in association with member cost share..$^{18}$ Members paying $\$ 100$ or less per prescription for MS medications were compared with patients paying more than $\$ 100$. The analysis found a significantly higher associated rate of prescription abandonment for MS patients paying more than $\$ 200$ per prescription compared with patients paying $\$ 100$ or less. ${ }^{18}$

Our benchmark analysis of pharmacy and medical claims data showed that the mean out-of-pocket patient expenditure per prescription claim for MS agents increased from $\$ 48$ per claim in 2006 to $\$ 82$ in 2009 (Table 2). ${ }^{7}$ Although the mean patient expenditure per prescription appears higher in 2010 than in 2009, the data are through 3 quarters and therefore are not representative of an entire year. Median patient expenditures per prescription are roughly one-half the mean expenditure and have risen minimally from $\$ 25$ in 2006 to $\$ 30$ in 2009. The discrepancy between mean and median patient expenditure per prescription claim is likely the result of 2 factors. First, Gleason et al. found that 13.8\% of patients filling prescriptions for MS biologic drugs paid more than $\$ 200$ per prescription, and $5.4 \%$ paid more than $\$ 500$ per prescription; these higher costs skew the mean upward relative to the median. Second, members pay higher out-of-pocket amounts early in the year when deductibles have not been met (Table 2). ${ }^{7}$ Nonadherence to therapy may increase the risk of relapse and associated disability. Payers should consider setting a maximum out-of-pocket limit of between $\$ 100$ and $\$ 150$ per prescription when utilizing a specialty tier for MS biologic agents.

MS is a potentially disabling disease, but treatment options are available. The article by Asche et $a .^{5}$ and others like it highlight the escalating costs associated with MS management. Price inflation continues to be the primary driver of increased pharmacy costs for MS patients. Opportunities exist for payers to manage the MS categories and control cost. Preferring select agents on formulary, developing utilization management programs to promote patient safety, and encouraging use of preferred agents and specialty pharmacies all provide opportunities to optimize clinical and service outcomes at the lowest cost.

\section{Authors}

JEREMY A. SCHAFER, PharmD, MBA, is Director of Formulary Development, and BRENT W. GUNDERSON, PharmD, is Senior Clinical Pharmacist, Prime Therapeutics LLC, Eagan, Minnesota. PATRICK P. GLEASON, PharmD, BCPS, FCCP, is Director of Clinical Outcomes Assessment, Prime Therapeutics LLC, Eagan, Minnesota, and Adjunct Associate Professor, College of Pharmacy, University of Minnesota, Minneapolis, Minnesota.

AUTHOR CORRESPONDENCE: Jeremy A. Schafer, PharmD, MBA, Director of Formulary Development, Prime Therapeutics LLC, 1305 Corporate Center Dr., Eagan, MN 55121. Tel.: 612.777.5097; Fax: 612.777.5143; E-mail: jschafer@primetherapeutics.com.

\section{DISCLOSURES}

There was no external funding for this manuscript. The authors are employees of Prime Therapeutics LLC, a pharmacy benefits management company whose ownership includes health plans.

Concept and design were performed by Gleason and Schafer. Data collection and interpretation were performed primarily by Gunderson with the assistance of Gleason and Schafer. The manuscript was written by Schafer with the assistance of Gleason and Gunderson, and revised by all 3 authors.

\section{REFERENCES}

1. Noseworthy J, Lucchinetti C, Rodriguez M, Weinshenker B. Multiple sclerosis. N Engl J Med. 2000;343(13):938-52.

2. Ryan M. Multiple Sclerosis. In: Dipiro JT, Talbert RL, Yee GC, Matzke GR, Wells BG, Posey LM, ed. Pharmacotherapy A Pathophysiologic Approach. New York, NY: McGraw Hill; 2008:431-441.

3. Pope GC, Urato CJ, Kulas ED, Kronick R, Gilmer T. Prevalence, expenditures, utilization, and payment for persons with MS in insured populations. Neurology. 2002;58(1):37-43.

4. Kobelt G, Berg J, Atherly D, Hadjimichael O. Costs and quality of life in multiple sclerosis: a cross-sectional study in the United States. Neurology. 2006;66(11):1696-702.

5. Asche CV, Singer ME, Jhaveri M, Chung H, Miller A. All-cause health care utilization and costs associated with newly diagnosed multiple sclerosis in the United States. J Manag Care Pharm. 2010;16(9):703-12. Available at: http://www.amcp.org/data/jmcp/703-712.pdf

6. Kunze AM, Gunderson BW, Gleason PP, Heaton AH, Johnson SV. Utilization, cost trends, and member cost-share for self-injectable multiple sclerosis drugs-pharmacy and medical benefit spending from 2004 through 2007. J Manag Care Pharm. 2007;13(9):799-806. Available at: http:// www.amcp.org/data/jmcp/JMCPMaga_N-D\%2007_799-806.pdf.

7. Internal data. Prime Therapeutics. Eagan, Minnesota. Pharmacy and medical claims data for approximately 9.0 million members, dates of service from January 1, 2006, through September 30, 2010.

8. Goldberg LD, Edwards NC, Fincher C, Doan QV, AL-Sabbagh A, Meletiche DM. Comparing the cost-effectiveness of disease-modifying drugs for the first-line treatment of relapsing-remitting multiple sclerosis. J Manag Care Pharm. 2009;15(7):543-55. Available at: http://www.amcp.org/data/ jmcp/543-555.pdf.

9. Bell C, Graham J, Earnshaw S, Oleen-Burkey M, Castelli-Haley J, Johnson K. Cost-effectiveness of four immunomodulatory therapies for relapsingremitting multiple sclerosis: a Markov model based on long-term clinical data. J Manag Care Pharm. 2007;13(3):245-61. Available at: http://www. amcp.org/data/jmcp/245-61.pdf. 
10. Ampyra (dalfampridine). Acorda. January 2010. Available at: http://www. accessdata.fda.gov/drugsatfda_docs/label/2010/022250s000lbl.pdf. Accessed October 29, 2010.

11. Wolters Kluwer Health. Medi-Span database. Accessed October 11, 2010.

12. U.S. Food and Drug Administration. FDA approves first oral drug to reduce MS relapses. September 22, 2010. Available at: http://www.fda.gov/ NewsEvents/Newsroom/PressAnnouncements/ucm226755.htm. Accessed October 29, 2010.

13. Association of British Neurologists. Revised (2009) Association of British Neurologists' guidelines for prescribing in multiple sclerosis. Available at: http://www.theabn.org/abn/userfiles/file/ABN_MS_Guidelines_2009_ Final(1).pdf. Accessed October 27, 2010.

14. Pohl D, Waubant E, Banwell B, et al. Treatment of pediatric multiple sclerosis and variants. Neurology. 2007;68(16 suppl 2):S54-S65.
15. Multiple Sclerosis Therapy Consensus Group (MSTCG), Wiendl H, Toyka KV, Rieckmann P, Gold R, Hartung HP, Hohlfeld R. Basic and escalating immunomodulatory treatments in multiple sclerosis: current therapeutic recommendations. J Neurol. 2008;255(10):1449-63.

16. Goodman AD, Brown TR, Krupp LB, et al. Sustained-release oral fampridine in multiple sclerosis: a randomised, double-blind, controlled trial. Lancet. 2009;373(9665):732-38.

17. U.S. Food and Drug Administration. NDA 22-250: fampridine AC backgrounder. September 16, 2009. Available at: http://www.fda. gov/downloads/AdvisoryCommittees/CommitteesMeetingMaterials/ Drugs/PeripheralandCentralNervousSystemDrugsAdvisoryCommittee/ UCM185663.pdf. Accessed October 27, 2010.

18. Gleason PP, Starner CI, Gunderson BW, Schafer JA, Sarran HS. Association of prescription abandonment with cost share for high-cost specialty pharmacy medications. J Manag Care Pharm. 2009;15(8):648-58. Available at: http://www.amcp.org/data/jmcp/648-658.pdf. 